\title{
Taşınabilir Fotovoltaik (PV) Sistem Tasarımı
}

\author{
İbrahim Kırbaş ${ }^{*}$ \\ 1* Burdur Mehmet Akif Ersoy Üniversitesi, Teknik Bilimler Meslek Yüksekokulu, Elektrik ve Enerji Bölümü, Burdur, Türkiye, (ORCID: 0000-0002-5560-638X), \\ ikirbas@mehmetakif.edu.tr
}

(İlk Geliş Tarihi 26 Nisan 2021 ve Kabul Tarihi 3 Ağustos 2021)

(DOI: 10.31590/ejosat.928200)

ATIF/REFERENCE: Kırbaş, İ. (2021). Taşınabilir Fotovoltaik (PV) Sistem Tasarımı. Avrupa Bilim ve Teknoloji Dergisi, (25), 675679.

\section{$\ddot{O} \mathbf{z}$}

Enerji üretimi için kullanılan kaynakların yarattığı çevresel sorunların aşılmasında ön plana yenilenebilir enerji kaynakları çıkmaktadır. Yenilenebilir enerji kaynaklarının bir diğer avantajı da, üretilen enerjinin iletim ve dağıtımı gibi sorunlarını da ortadan kaldırmasıdır. Özellikle şebekenin ulaştırılmasında güçlük yaşanan bölgelerde bireysel kullanım için kurulan sistemler ile sorun çözüme ulaştırılmaktadır. Günümüzde bir evin elektrik ihtiyacını karşılamak için yapılmış paket sistemler bulunmaktadır. Fakat bu sistemler daha çok çatı üzerinde ya da arazide sabit konumda olan sistemlerdir. Bu çalışmada tasarlanan taşınabilir Fotovoltaik (PV) sistem ile hem bir evin elektrik ihtiyacı karşılanabilecek hem de yaylacılık, arıcılık, çadır kampı, tarımsal sulama gibi değişik amaçlı ve farklı bölgelerde enerji üretimi mümkün olacaktır. Sistem maliyeti hali hazırda olan paket sistemler ile yaklaşık hatta aynı maliyette olmasıyla bir dezavantaj oluşturmazken, taşınabilir olması ise en büyük avantajıdır.

Anahtar Kelimeler: Yenilenebilir enerji, Güneş, PV sistem, Taşınabilir sistem.

\section{Portable Photovoltaic (PV) System Design}

\begin{abstract}
Renewable energy sources come to the forefront in overcoming the environmental problems caused by the sources used for energy production. Another advantage of renewable energy sources is that they eliminate the problems of transmission and distribution of the energy produced. Especially in regions where there is difficulty in the delivery of the network, the problem is solved with the systems established for individual use. Today, there are package systems designed to meet the electricity needs of a house. However, these systems are mostly fixed on the roof or in the field. With the portable Photovoltaic (PV) system designed in this study, it will be possible to meet the electricity need of a house and to generate energy for different purposes and in different regions such as transhumance, apiculture, tent camp, agricultural irrigation. The cost of the system does not create a disadvantage as it is approximately the same cost as the current package systems, and its portability is its biggest advantage.
\end{abstract}

Keywords: Renewable energy, Solar, PV system, Portable system.

\footnotetext{
*Corresponding Author: ikirbas@mehmetakif.edu.tr
} 


\section{Giriş}

İnsanlık gelişen teknolojiye uyum sağlamak ve yaşamını sürdürmek için enerjiye ihtiyaç duyar. $\mathrm{Bu}$ ihtiyaç duyduğu enerjiyi içinde bulunduğu doğadan doğrudan olarak ya da dolaylı (türeterek) elde eder (Kırlı ve Kulu, 2016). Son zamanlara kadar kullanılan en önemli enerji kaynakları fosil kökenli olanlardı. 1970 yıllarda ve daha sonraki yıllarda fosil kökenli enerji kaynaklarının doğaya ve çevreye olan olumsuzlukları nedeniyle insanoğlu daha temiz ve çevre dostu enerji kaynaklarının arayışına başladı (Akyazı ve ark., 2019; Güner ve Muharremoğlu, 2020). Güneş, rüzgâr, jeotermal, hidrolik ve deniz kaynaklı enerji kaynaklarını yenilenebilir enerji kaynakları olarak kullanmaya başland. Yenilenebilir enerji kaynakları olarak nitelendirilen her bir enerji kaynağının kullanılması için farklı teknolojilere ihtiyaç vardır. Güneş kollektörleri, fotovoltaik paneller, rüzgâr türbinleri, buhar türbinleri, gelgit akış jeneratörü bunlardan en bilinenleridir. Ayrıca bu enerji kaynaklarının içinde en geniş kapsamlı çalışma alanı olan ve bitmeyecek büyüklükte olan güneştir. Yapılan araştırmalar güneşten gelen 1şınımların $40 \mathrm{dk}$ boyunca depolanması ile dünyanın bir yıllık enerji ihtiyacının karşılanabileceğini bildirmektedir (Kılıç, 2015).

Ülkemizde güneş enerjisi genellikle kullanım sıcak suyu elde edilmesi ve ürün kurutmada etkin olarak kullanılmaktadır. Son y1llarda bunlara ek olarak güneş enerjisinden elektrik üretimi dikkat çekmektedir. Yasal düzenlemeler yapılması, teşvikler verilmesi, şebekeye elektrik satılmasına olanak verilmesi gibi elektrik üretimi ile ilgili konularda oldukça önemli adımlar atılmıştır. Her geçen gün bu alanda yapılan yatırım miktarı artmakta ve yıllık elektrik üretiminde güneş enerjisi ile üretilen elektrik enerjisi oranı da artmaktadır. Tabi ki tüm bunlarda Türkiye'nin coğrafi konumunun da payı oldukça önemlidir.

Türkiye'nin Güneş Enerjisi Potansiyeli Atlası (GEPA) verileri bize gösteriyor ki Türkiye günlük toplam 7,5 saat, yıllık toplam 2.741 saat güneşlenme süresine sahiptir. Ayrıca günlük toplam $4,18 \mathrm{kWh} / \mathrm{m}^{2}$, yıllık toplam $1.527 \mathrm{kWh} / \mathrm{m}^{2}$ gelen güneş enerjisi değerlerine sahiptir (URL-1, 2021). Enerji bakanlığının verilerinden de anlaşılacağı gibi Türkiye'nin ortalama güneşlenme süreleri oldukça yüksek bir değerdedir. Bölgesel olarak ise Güneydoğu Anadolu bölgesi birinci sırada yer alırken bunu ikinci sırada Akdeniz bölgesi üçüncü sırada Doğu Anadolu bölgesi takip etmektedir (Kırbaş ve ark., 2013).

Fotovoltaik (PV) paneller güneş enerjisinden elektrik üretimi için kullanılan aygıtlardır (Çifci ve ark., 2014). Fotovoltaik sistemler her türlü kapasiteye uygun olarak tasarlanabilir. Bir tek lambanın enerji ihtiyacını karşılayabildiği gibi güneş enerjisi santrali (GES) şeklinde bir bölgenin enerji ihtiyacını da karşılayabilir. PV panelleri ticari amaçlı da kullanabilirsiniz, bireysel olarak ta kullanabilirsiniz. Bireysel sistemlerin amortisman süreci 7-8 yıldan fazla sürdüğü için kullanıcılar süreyi uzun bulmakta ve tercih etmemektedirler. Fakat şebekenin olmadığı, jeneratör için yakıt taşımanın zahmetli olduğu bölgelerde amortisman süreci göz ardı edilerek tercih edilmektedir. $\mathrm{Bu}$ tür sistemler gerekli kapasite hesab1 yapıldıktan sonra yeterli sayıda fotovoltaik panel, gece kullanımı için depolama amaçlı akü, DC gerilimi AC gerilime çevirmek için inverter ve şarj kontrol ünitelerinden oluşur (Akcan ve ark., 2020).

PV paneller ile elektrik üretimi için diş havanın sıcaklığı ve nemi oldukça önemli değişkenlerdir. Dış hava sıcaklığının fazla olması (Temmuz, Ağustos ayları gibi) verimi olumsuz yönde etkilemektedir. İdeal bir verim daha çok ş̧ınım değerleri yüksek fakat düşük hava sıcaklığında $\left(25^{\circ} \mathrm{C}\right.$ altında $)$ ve $\% 50$ bağıl nemli zamanlarda (bahar aylarında) elde edilmektedir (Köse, 2018). Başay ve ark. (2019) yapmış oldukları çalışmalarında orta yükseklikte dağlık alanlarda kurulan panellerin ömrüne 1şınım, sıcaklık ve nem gibi etkenlerin etkisini araştırmışlardır. Deniz seviyesinde kullanılan bir panel ile 835 m yüksekte kurulan bir paneli karşılaştırmışlar. Dağlık alanda yüksekte kurulan panellerin ömründe nem ve sicaklık bakımından sirasıyla \%5,8'lik ve \%10'luk bir uzama olacağını tespit etmişlerdir (Başay ve ark., 2019). Yaylacılık ve arıcılık faaliyetlerinin yürütüldüğü yüksek kesimler uygun sıcaklık ve nem değerleri sağlamaktadır. Bunun anlamı da bu bölgelerde kullanılacak olan PV sistemlerinden yüksek verimle faydalanılacağıdır.

$\mathrm{Bu}$ çalışmada; şebeke geriliminin olmadığı ücra yerlerde özellikle yaylacılık, arıcılık ve tarımsal sulama alanlarında kullanılabilecek aynı zamanda ergonomik boyutlarda taşınabilir bir fotovoltaik sistem tasarımı yapılması amaçlanmıştır. Tasarlanan bu sistem konut, yazlık, ağıl, ahır ya da çadır gibi yapılarda bulunacak minimum sayıdaki cihazların elektrik enerjisini karşılayabilecek kapasitededir. Çevresel sorunlar yaratmaması, montaj maliyeti ve bakım masraflarının olmaması sistemin diğer avantaları arasındadır.

\section{Materyal ve Metot}

PV sistemin kapasitesinin belirlenmesi için kullanılacak olan elektrikli aletlerin ne kadar enerji tükettiği ve günlük olarak ne kadar enerji ihtiyacı olduğunun belirlenmesi gerekmektedir. $\mathrm{Bu}$ sebeple bir yayla evinde ya da yazlık olarak tabir edilen bir yapıda olması gereken minimum elektrikli cihazların listesi ve elektrik tüketimi Tablo 1'de verilmiştir. Yük olarak kabul edilen yapının günlük ortalama elektrik tüketimi $0,528 \mathrm{kWh}$ 'dir. $\mathrm{Bu}$ elektrik tüketimi yaylacılık yapan, arıcılık yapan kişilerinde elektrik ihtiyacını rahatlıkla karşılayabilecek kapasitedir. Ayrıca tarımsal sulama için $0,7 \mathrm{hp}$ gücüne kadar bir pompaya rahatlıkla enerji sağlayabilecek bir sistemdir.

Tablo 1. Elektrikli aletlerin enerji tüketimi (URL-2, 2021; URL-3, 2021; URL-4, 2021)

\begin{tabular}{|l|c|c|c|c|c|}
\hline \multicolumn{1}{|c|}{ Cihaz } & $\begin{array}{c}\text { Güç } \\
\text { (Watt) }\end{array}$ & Adet & $\begin{array}{c}\text { Çalışma } \\
\text { süresi } \\
\text { (Saat) }\end{array}$ & $\begin{array}{c}\text { Günlük Ortalama } \\
\text { Enerji Tüketimi } \\
\text { (Wh) }\end{array}$ & $\begin{array}{c}\text { Günlük Ortalama } \\
\text { Enerji Tüketimi } \\
\text { (kWh) }\end{array}$ \\
\hline Mini Buzdolab1 (A+) & 12,5 & 1 & 24 & 300 & 0,300 \\
\hline LED TV (A+) (55 cm) & 25 & 1 & 4 & 100 & 0,100 \\
\hline Led Lamba & 8 & 3 & 4 & 96 & 0,096 \\
\hline Telefon Şarj1 & 4 & 2 & 4 & 32 & 0,032 \\
\hline \multicolumn{7}{|r|}{ TOPLAM } & 528 & 0,528 \\
\hline
\end{tabular}


Günlük ortalama elektrik ihtiyacı $0,528 \mathrm{kWh}$ olarak belirlenmiştir. PV sistemde kullanılacak olan panel gücü, adedi ve büyüklüğü, akü grubu, inverter ve şarj kontrol ünitesi gibi bileşenlerin belirlenmesinde PVsyst isimli yazılımın 6.8.8 versiyonundan faydalanılmıştır. Sistem şebeke elektriğinin olmadığ bölgelerde çalıştırılacak olup Off-Grid diye tabir edilen kapalı sistem olarak çalışacaktır. Ayrıca gündüz sistemden üretilen elektrik enerjisinin bir kısmı akülerde depolanacaktır. Bu sayede gece, kapalı havalarda ve arka arkaya yağışlı geçen 2 gün boyunca kesintisiz elektrik sağlayacak şekilde tasarlanmıştır.

\section{Araştırma Sonuçları ve Tartışma}

\subsection{PV Sistem Bileșenlerinin Belirlenmesi}

Sistem bileşenlerinin ve kapasitelerinin belirlenmesinde kullanılan PVsyst 6.8.8 isimli programda öncelikle bölge seçimi ve 1şınım miktarlarının sisteme tanıtılması yapılmıştır. Işınım miktarlarının elle girilebileceği gibi bölge koordinatları girilerek Meteonorm verilerinin kullanımı da mümkündür. Bu çalışmada arıcılığın ön planda olduğu Muğla ili ve yaylacılık faaliyetleri yapılan Toroslar'da belirlediğimiz iki bölge için ayrı ayrı tasarım yapılmıştır. Bölgelerin 1şınım miktarları için Meteonorm 7.2 (2004-2010) verileri kullanılmıştır. İkinci adım olarak günlük tüketiciler ile ilgili bilgilerin girişi yapılmıştır (Şekil 1). Bir sonraki adımda PV paneller için uygun açının (Tilt) belirlenmesi yapılmıştır. Meteonorm verileri ve Muğla ilindeki belirlenen bölgenin koordinatları ile sistem tarafından yaz mevsimi için hesaplama yapılmış ve panel açıs $20^{\circ}$ olarak belirlenmiştir (Şekil 2). Günlük tüketim profili Şekil 3 'te verilmiştir. Şekil 3 incelendiğinde tüketimin 19-23 saatleri arasında üst seviyelere ulaştığı görülmektedir.

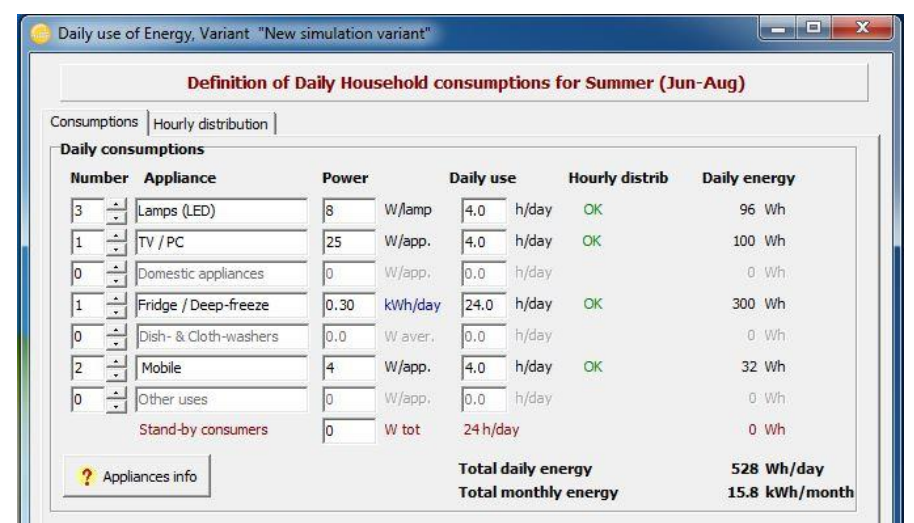

Şekil 1. Günlük tüketicilerin harcamış oldukları elektrik enerjisi

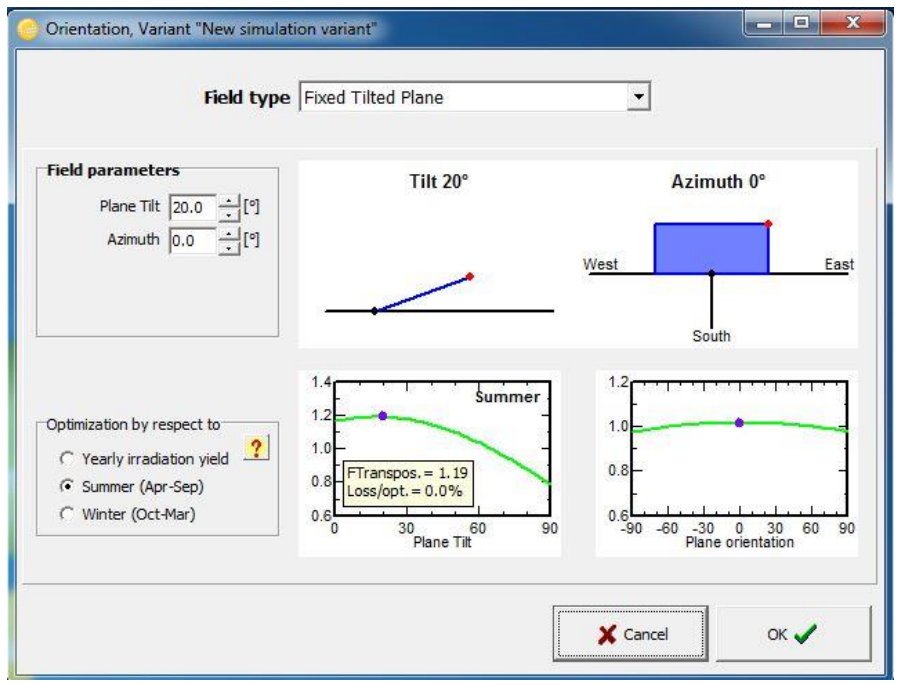

Şekil 2. Panel açısının hesaplanması

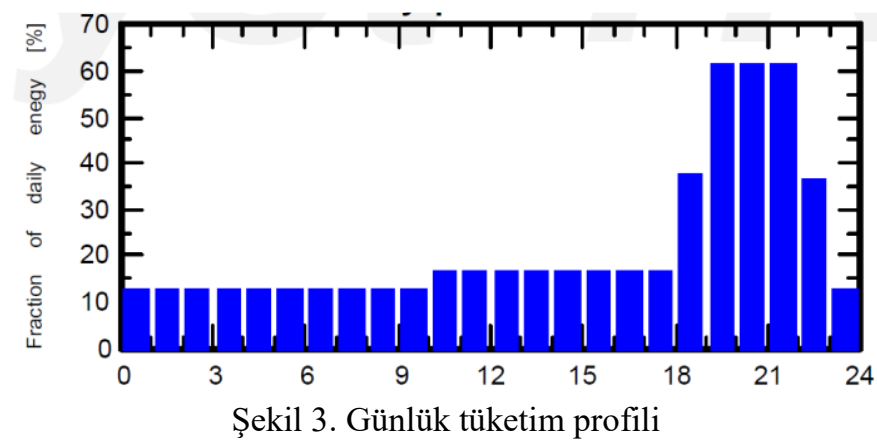

Günlük ortalama 0,528 kWh elektrik üretimi için PVsyst programında yapilan hesaplamalar sonucu belirlenen ana sistem elemanları Şekil 4'te görülmektedir. 2 adet 280 W'lık polikristal panel, 2 adet derin döngü jel akü, $1200 \mathrm{~W}$ gücünde bir inverter ve bir adet şarj kontrol cihazı gerektiği belirlenmiştir. Yapılan fiyat araştırması sonucunda, belirlenen taşınabilir PV sistem bileşenlerine ait özellik ve fiyat bilgileri Tablo 2'de verilmiştir.

\begin{tabular}{|l|l|}
\hline PV saha yönlendirmesi & Eğim 20 $0^{\circ}$ Azimut $0^{\circ}$ \\
\hline PV panel modeli & AZ6-60-280MS/1000V 280Wp \\
\hline PV panel sayıs1 & 2 adet, Toplam 560Wp \\
\hline Akü & Li-on, 13 V 100 Ah \\
\hline Akü sayıs1 & 2 adet, Toplam 13V/ 200 Ah \\
\hline Kullanıcıların ihtiyac1 & $193 \mathrm{kWh} /$ yıl \\
\hline \multicolumn{2}{|c|}{ Şekil 4. Ana sistemin değişkenleri }
\end{tabular}

Tablo 2. Taşınabilir PV sistemine ait bileşenlerin özellikleri ve fiyatları

\begin{tabular}{lcccc}
\hline & Özellikleri & Adet & $\begin{array}{c}\text { Fiyat } \\
\text { (TL) }\end{array}$ & $\begin{array}{c}\text { Toplam Tutar } \\
\text { (TL) }\end{array}$ \\
\hline Polikristal Panel & $\begin{array}{c}280 \mathrm{~W} \\
1640 \times 990 \times 35 \mathrm{~mm} / 18 \mathrm{~kg}\end{array}$ & 2 & 660 & 1320 \\
\hline $\begin{array}{c}100 \mathrm{Ah} \\
\text { Jel Akü }\end{array}$ & $\begin{array}{c}328 \times 172 \times 220 \mathrm{~mm} / 2,9 \mathrm{~kg} \\
1200 \mathrm{~W}\end{array}$ & 2 & 1300 & 2600 \\
\hline İnverter & $265 \times 200 \times 97 \mathrm{~mm} / 2,2 \mathrm{~kg}$ & 1 & 540 & 540 \\
\hline $\begin{array}{c}30 \mathrm{~A} \\
\text { Şarj Kontrol Cihaz1 }\end{array}$ & $187 \times 99 \times 50 \mathrm{~mm} / 0,37 \mathrm{~kg}$ & 1 & 220 & 220 \\
\hline & & GENEL TOPLAM & $\mathbf{4 6 8 0}$ \\
\hline
\end{tabular}




\subsection{PV Sistemi Taşıyıcı Gövdenin Tasarımı}

Sisteme ait bileşenlerin montaj resmi açık görünümü Şekil 5 'te görülmektedir. Her bir panel alt kısımda mafsallı iki adet kol ile alt gövdeye bağlıdır. Mafsallar sayesinde panellerin konumu açık ve kapalı olmak üzere iki kademeli olarak ayarlanabilmektedir. Aynı zamanda panelleri taşıyan mafsallı ayakların uzunlukları sayesinde panneller $20^{\circ}$ lik açı (Tilt $20^{\circ}$ ) ile konumlandırılabiliyor. Alt gövde üzerinde sabit konumda iki adet akü ve bir inverter bulunmaktadır.
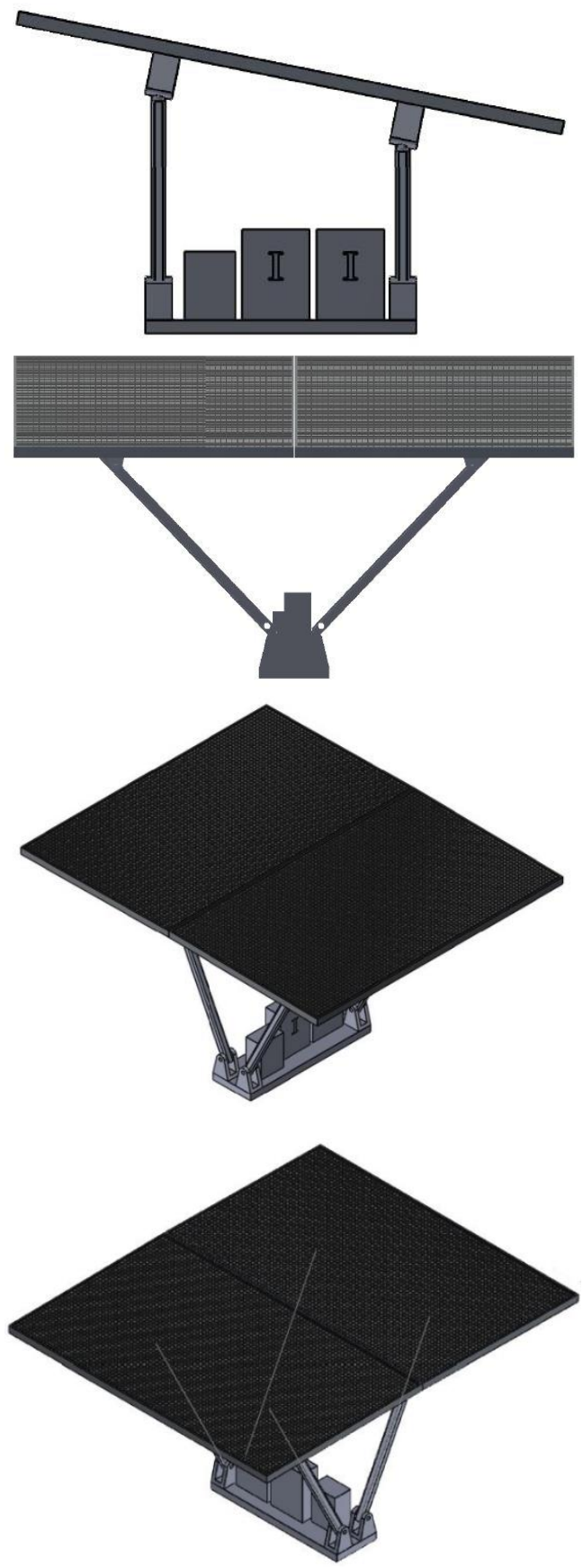

Şekil 5. Sistemin açık görünümü (yan, ön ve üst görünüm)

Sistemin kapalı görünümü ise Şekil 6'da verilmiştir. Toplam ağırlık 44,37 kg sistem bileşenleri ve gövde profilleri ile birlikte 50 kg'dır. $2220 \times 320 \times 1660 \mathrm{~mm}$ boyutlarında $1,18 \mathrm{~m}^{3}$ hacminde bir taşıma sandığ ile rahatlıkla taşınabilmektedir.
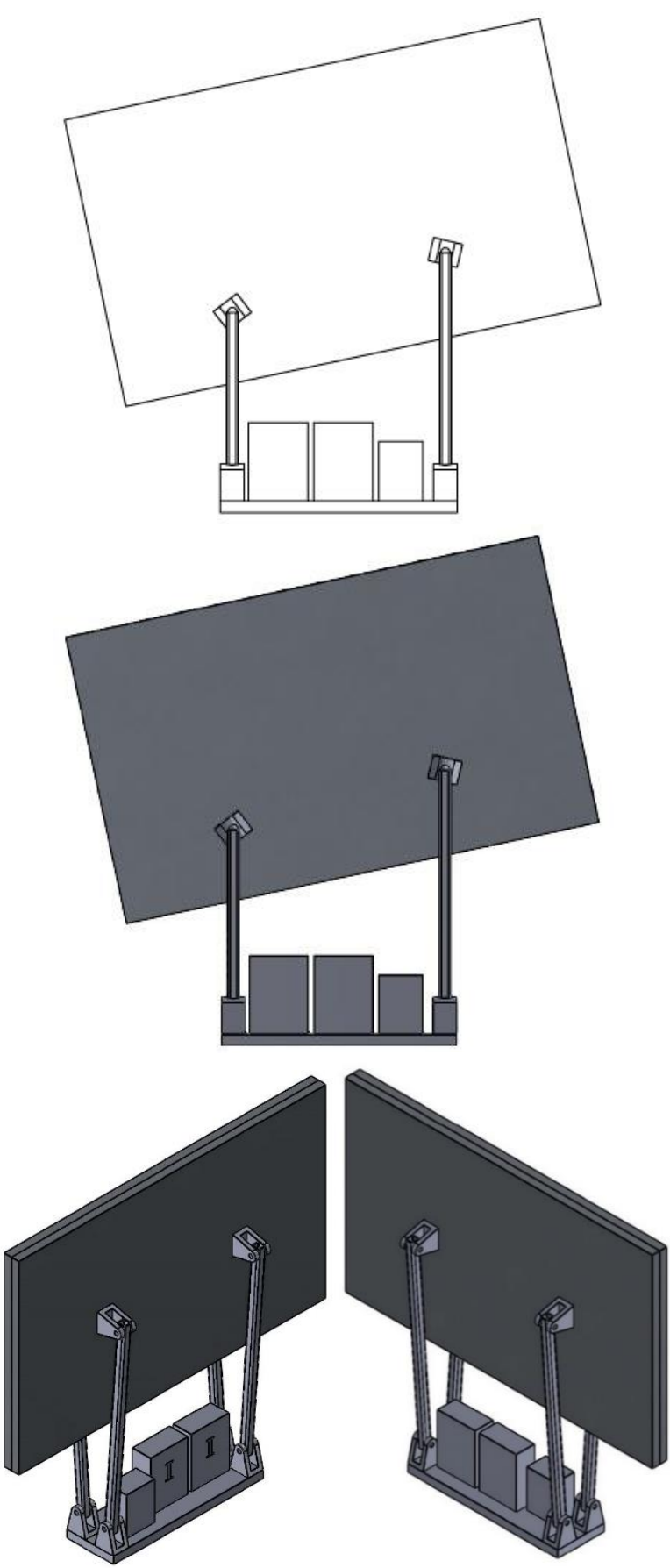

Şekil 6. Sistemin kapalı görünümü

Tasarlanan taşınabilir PV sistemi maliyeti 4.680 TL sistem bileşenleri ve 300 TL taşıyıcı profil gövde olmak üzere 4.980 TL dir. Piyasada paket olarak satılan $0,5 \mathrm{~kW}$ 'lık sistemlerin fiyatı da 5.000-6.000 TL aralığındadır. Genellikle 3 adet panel, iki adet akü, inverter ve şarj kontrol ünitesinden oluşmaktadır (URL-5, 2021). Kurulum yapılan yerde sabit olarak kalmaktadır. Kurulum için ekstra ücret ödemesi yapılmaktadır. Bu tasarlanan taşınabilir PV sistem ise herhangi bir kurulum ücreti gerektirmez, iki adet panel ile daha az parçadan oluşur ve ihtiyaç duyulan her yere götürülebilir.

Arıcılık yapan kişiler sürekli aynı alanlarda kalmayarak sende en az iki sefer yer değişikliği yaparlar. Muğla Arı Yetiştiricileri Birliği (MAYBİR), kayıtlı üye sayısının 1 milyonun üzerinde olduğunu ve Muğla ili her yıl ortalama 3 
milyon üzerinde arıcıya ev sahipliği yaptığını açıklamıştır. Çam balı üretiminde ise Türkiye'nin \%92 sini Dünya'nın ise \%70'i oranında üretim yapıldığını bildirmişlerdir (URL-6, 2018). Öztürk (2017), Arıcılı̆̆ın teknik özelliklerinin belirlenmesi üzerine yapmış olduğu çalışmasında arıcılık yapan kişiler ile yüz yüze anket yöntemiyle yaptığı görüşmeler sonucunda, ankete katılan kişilerin Muğla ili sınırlarında ve dışında ortalama 100400 kovan ile gezginci arıcılık faaliyetleri sürdürdüklerini tespit etmiştir. Muğla ili dışında yapılan yer değiştirmelerde ise öncelikli olarak Aydın, Afyon, Konya ve Isparta illerini tercih ettiklerini bildirmiştir (Öztürk, 2017). Böylesine önemli oranda bal üretim yapan ve bu üretimi gezginci arıcıllk metoduyla yapan kişilerin enerji ihtiyacını karşılamak için taşınabilir PV sistem oldukça uygun görünmektedir.

Yaylacılık, yüksek bölgelerdeki geçici yerleşme şeklidir (Doğanay, 2010). Yaylacılık kültürünün yaşatıldığı bölgeler sıralamasında Doğu Karadeniz başta olmak üzere bunu Akdeniz, Ege ve İç Anadolu izlemektedir. İnsanlar değişik amaçlar için yaylalara göç ederler. Bazı bölgelerde hayvanlarının yiyecek ihtiyacını karşılamak için yüksek kesimlerdeki meralardan faydalanmak, hayvanlarını otlatmak ve hayvanların kışlık yiyeceklerini toplamak için yaylaya göç edilir. Bazı bölgelerde ise yaylacılık, doğa ile baş başa olma, sağlıklı yaşam ve serin bir yer arayışıdır (Daşçı ve Çomaklı, 2006). Çok uzun yıllardır bir yaşam şekli olarak süregelen yaylacılık uzun yıllarca da devam edecektir. Hangi amaçla olursa olsun yaylalara giden ve orda belirli bir dönem yaşayan insanların teknolojik ihtiyaçlarının karşılanması gerekir. Bir yayla evine sahip olabilirsiniz ya da bir kıl çadırda yaşayabilirsiniz. Aydınlanma, cep telefonu şarjı ve TV gibi aletlerin elektrik gereksinimleri taşınabilir PV sistem ile karşılanabilir.

Tarımsal ürünlerin suya ihtiyacı olduğu sıcak yaz günlerinde bol miktarda bulunan güneş enerjisinden elektrik üretmek ve bunu da tarımsal sulamada kullanmak oldukça mantıklı olacaktır. Tarımla uğraşan kişilerin tek bir yerde arazileri olmayı farklı farklı yerlerdeki arazilerinde tarımla uğraşmaktadırlar. Her bir arazi için PV sistem satın almak yerine böylesi taşınabilir PV sistem ile hangi arazide çalışacaksa ihtiyacı olan elektrik enerjisini üretebilecektir. Üretmiş oldukları bu enerjiyi tarımsal sulama için pompaya güç sağlamada, cep telefonu şarj etmekte ve akşam saatlerinde aydınlanma gibi alanlarda kullanabileceklerdir.

Taşınabilir PV sistemin bir diğer avantajı da kullanılmadığı zamanlarda (özellikle kış aylarında) katlanıp kapalı bir yere taşınmak suretiyle olumsuz hava koşullarından etkilenmemesidir. Yayla alanlarında yüksek rakımlarda oluşan kar, yağmur, dolu gibi yağışlar sabit olan bir sistemde panel içinde istenmeyen mikro çatlaklar oluşturur ve don gibi olaylar panel malzemesinin içyapısını bozar. Bu şekildeki hava olayları panelin verimin ve ömrünü azaltır. Taşınabilir PV sistemler ile buna benzer sorunlar çözüme ulaşır.

\section{Sonuç}

En ufak bir konutta olması gereken elektrikli aletler göz önüne alınarak belirlediğimiz sistem kapasitesine göre taşınabilir PV sistemi tasarımı yapılmıştır. Sistem yenilenebilir enerji kaynaklarından olan güneş enerjisinden elektrik üretmesi, çevreye olan $\mathrm{CO}_{2}$ salınımın hiç olmaması gibi önemli özellikler taşımaktadır. Fakat en önemli özelliği ise şebeke elektriğinin olmadığı yerlerde elektrik ihtiyacını karşılamasıdır. Benzer kapasitedeki sistemlerden daha düşük maliyette, düşük hacimli

e-ISSN: 2148-2683 olması ve taşınabilir olması ile ön plana çıkmaktadır. Özellikle yaylacılık, arıcılık ve tarımsal sulama alanında uğraşan kişilerin elektrik ihtiyacını rahatlıkla karşılayabilecektir. Kapmçılık, karavan turizmi gibi diğer faaliyetler içinde kullanımı mümkündür.

\section{Kaynakça}

Akcan, E., Kuncan, M., \& Minaz, M.R. (2020). Pvsyst Yazılımı ile $30 \mathrm{~kW}$ Şebekeye Bağlı Fotovoltaik Sistemin Modellenmesi ve Simülasyonu. Avrupa Bilim ve Teknoloji Dergisi, (18), 248-261.

Akyazı, Ö., Şahin, E. \& Kahveci, D. C. (2019). Fotovoltaik Panel ve Şebeke Entegrasyonlu Akıllı Sokak Lambası Tasarımı ve Uygulaması. European Journal of Science and Technology, (Özel Sayı), 356-360.

Başay, V., Eken, R., \& Yılmaz, G. (2019). Orta Yükseklikte Dağlık Bölgelerde Kurulan Güneş Enerjisi Santralinde Fotovoltaik Modüllerin Yaşlanmasının Araştırılması. Uludağ Üniversitesi Mühendislik Fakültesi Dergisi, 24(2), 325-336

Çifci, A., Kırbaş, İ., \& İşyarlar, B. (2014). Güneş Pili Kullanılarak Burdur'da Bir Evin Ortalama Elektrik İhtiyacının Karşılanması, Burdur Mehmet Akif Ersoy Üniversitesi Fen Bilimleri Enstitüsü Dergisi, 5(1), 14-17.

Daşçı, M., \& Çomaklı, B. (2006). Yaylacılık ve Tarımsal Açıdan Önemi. Atatürk Üniversitesi Ziraat Fakültesi Dergisi, 37(2), 275-280.

Doğanay, S. (2010). İşlevsel değişim sürecinde Çakırgöl çevresinde yaylalar ve yaylacilık. Uluslararası Insan Bilimleri Dergisi, 7(2), 611-639.

Güner, S. \& Muharremoğlu, A. (2020). Bir Havalimanı Otoparkına Kurulabilecek Fotovoltaik Üretim Sisteminin Tasarımı ve Enerji Analizi. Avrupa Bilim ve Teknoloji Dergisi, (19), 182-188.

Kılıç, F.Ç. (2015). Güneş Enerjisi, Türkiye'deki Son Durumu ve Üretim Teknolojileri. Mühendis ve Makina, 56(71), 28-40.

Kırbaş, İ., Çifci, A., \& İşyarlar, B. (2013). Burdur İli Güneşlenme Oranı ve Güneş Enerjisi Potansiyeli. Burdur Mehmet Akif Ersoy Üniversitesi Fen Bilimleri Enstitüsü Dergisi, 4(2), 20-23.

Köse, E. (2018). Fotovoltaik Sistemlerin Sıcaklığa Bağlı Enerji Verimliliği Performansının Analiz Edilmesi. Dünya Multidisipliner Araştırmalar Dergisi, 2, 39-53.

Öztürk, A.İ. (2017). Muğla İli Ula İlçesi Arıcılı̆̆ının Bazı Teknik Özelliklerinin Belirlenmesi. Hayvansal Üretim, 58(2),52-57.

URL-1 (2021). Türkiye'nin Güneş Enerjisi Potansiyeli Atlası (GEPA). https://enerji.gov.tr/bilgi-merkezi-enerji-gunes (Erişim tarihi: 03.02.2021)

URL-2 (2021). Elektrikli aletlerin enerji tüketim. https://encazip.com/evdeki-aletler-ne-kadar-elektrik-tuketir (Erişim tarihi: 05.02.2021)

URL-3 (2021). Elektrikli aletlerin enerji tüketimi. https://www.enerjibes.com/elektrikli-aletler-kac-watt-harcar/ (Erişim tarihi: 05.02.2021)

URL-4 (2021). Elektrikli aletlerin enerji tüketimi. https://www.endamer.com/haber/elektrikli-ev-aletleri-nekadar-enerji-harcar (Erişim tarihi: 05.02.2021)

URL-5 (2021). Mini solar sistem. https://mundasolar.com/urun/mini-solar-sistem-05kw-offgrid/ (Erişim tarihi: 09.02.2021)

URL-6 (2018). Muğla Arı Yetiştiricileri Birliği (MAYBİR). https://www.hurriyet.com.tr/aricilarin-konaklama-yerleribelirleniyor-40883864 (Erişim tarihi: 11.02.2021) 